\title{
Reimaging and Rebuilding Primary Care as a Common Good
}

\author{
Megan R. Maboney, MD
}

(J Am Board Fam Med 2021;34:1042-1044.)

Keywords: Delivery of Health Care, Primary Health Care, Quality of Health Care

It is old news that we spend more than we get from our health care system. Yet, both history and current headlines demonstrate that crisis is often a prelude to transformation. I read the National Academies of Sciences, Engineering, and Medicine's Rebuilding the Foundations of Health Care report ${ }^{1}$ with tremendous excitement and recognized a critical juncture. The report conscientiously and passionately outlines a plan to reimagine and vitalize primary care in the United States for the greatest common good. My enthusiasm is tempered by the audacity and scope of the task.

When I read the report's bold assertion that primary care should be considered a common good in the United States, I thought about a recent visit to Rwanda. Rwanda is a dramatic and fascinating example of a society moving forward from collective devastation toward collective good. Months before the pandemic, I was on sabbatical in Rwanda, looking out the window of a Land Rover on my way to visit a rural district hospital, moved by the beauty of the verdant rolling hills. In the last 25 years, Rwanda has developed a highly effective health care delivery system. What this recovering country with modest resources has implemented and accomplished is instructive now as Americans respond to the inadequacies of our own health care system revealed during the Coronavirus disease 2019 (COVID-19) crisis.

From the Family Medicine, Stanford University, Palo Alto, CA (MRM).

Conflict of interest: None.

Corresponding author: Megan R. Mahoney, MD, 500 Pasteur Drive, Executive Suite, Palo Alto, CA 94304, Telephone: 650-725-3038, Fax: 650-498-9000 (E-mail: mahoneym@stanford.edu).

See Related Article on Page 886.
Rwanda is among the few countries to have achieved universal health coverage due to investments in primary care and its vision for an equitable, comprehensive, and integrated health system. The Ministry of Health led this massive effort by leveraging community health workers, training the pipeline of health care providers and leaders in a community-based context, and employing cuttingedge telehealth. They discovered the integrating and connecting power of technology and teams. Rwanda launched the University of Global Health Equity to train physicians in a community context because they recognized that the digital health revolution and team-based care would enable them to achieve high-impact population health benefits for all citizens. Rwanda is now providing unprecedented access with major measurable improved health outcomes.

Now is America's opportunity to leverage primary care for the greater good. With increasing sophistication and ease, primary care providers are demonstrating the potential of teams and technology. We are integrating new members-behavioral health clinicians, pharmacists, community health workers, etc.-into our teams. New team members are helping us reflect the population we serve practice and community-relevant care. We are tracking vital signs and delivering care at any location. Increasingly we are using point-of-care devices, such as ultrasounds and diabetic retinopathy scanners in our clinics. Add e-consults for efficient connection to specialists and user-friendly patient portals to have e-visits with patients, and the vision for how to deliver lower cost and higher quality health care becomes clear.

I write this commentary from the center of Silicon Valley, a locale with both an extreme 
privilege and corresponding poverty. Yet, this is the global epicenter of innovation. The same human ingenuity that harnesses new ideas also distributes new values and tools to the entire population. Here it is said change is a catalyst for more change. By restructuring primary care, and family medicine, specifically, as teamwork in the community, as the fundament of the common good, we can evolve collective ideas about health and health care engagement. We can provide whole-person care only if we only have access to understanding and supporting the whole community through teams.

The Rebuilding the Foundations of Health care report rightly called "bizarre" the slow use of telemedicine before the COVID-19 pandemic. In 2020, telemedicine became the lifeline for our patients and us, for both COVID-19 and every other human malady. We learned diagnosis and prescription delivery could take place faster than a Grubhub delivery. Telemedicine increases patient participation, medical literacy, and patient education, and builds trust and deeper insight into a patient's life or home circumstance. Telemedicine is 1 of many tools that increase ongoing personal contact and promotes understanding the individual in relation to family and community.

We cannot wait for 25 years for study cycles. For the first time in American history, the mortality rate is worsening, and the burden of poorly controlled chronic diseases is overwhelming budgets. Simultaneously this trend has the collateral effect of limiting the ability of the government to support social efforts, such as child care, education, infrastructure, and address climate change and racial injustice-all determinants of health increasing illness.

Change is in the works to reverse the chronic underinvestment of primary care, as the logic emerges those new priorities in our health care system must be established to ensure a solid foundation of our health care system. Presently in the United States, primary care handles a third of patient contact, ${ }^{2}$ with only $5.4 \%$ of the health care dollars, ${ }^{3}$ compared with an average of $7.8 \%$ among Organisation for Economic Co-operation and Development (OECD) nations ${ }^{4}$ and $38 \%$ in Rwanda. ${ }^{5}$ Primary care suffers from a lack of federal coordinating capacity, little dedicated research support, and a shrinking workforce pipeline. Primary care stakeholders-all of us-are positioned to orchestrate and lead this change.
Any implementation plan must include public outcry about the necessity of primary care as a common good.

Primary care as a common good is premised on the principle that the health of individuals affects the well-being of the community; therefore, robust health is a collective benefit. Primary care workforce should reflect the communities they serve and ensure that the care delivered is culturally appropriate. Electronic health records must be interoperable. Effective partnership with public health systems and community-based organizations is required.

Primary care as a common good can model services from fire departments to libraries that exist for all to protect and provide. The new vision outlined in the report stresses and demonstrated that a common good provides access to all. Primary care is not just a point of first contact but a vital ongoing longitudinal relationship strengthening over time. Yet, in crisis, the dramatic shortfall of who is served and who suffers was indisputable. Health equity can only be achieved by eliminating barriers to access. I have been a frontline witness to those disparities worldwide, and they are the most inexcusable in a country with the opportunity to solve and lead.

This Rebuilding the Foundations of Health Care report comes out in 2021 in the reality that Medicare's Trust Fund is projected to be depleted by $2026 .^{6}$ I applaud the efforts of the committee to address a long-term problem with fresh determination and concrete action steps. The report's vision unifies a playing field and defines the roles of all other players, from community health workers to specialists. Now is the time for all health care stakeholders to lean in and push for a shift away from fee-for-service mechanisms toward value-based and accountable payment, even though the path might be complex. We, as family physicians, are tasked with solving complex social and structural problems with the same skills we use to solve medical issues.

Many of the beauties of the vision put forth in the report include how national policy and resources, collective sharing of technological innovation, and information sharing can be managed and designed for individual and community choice, needs, and benefits. As consumer sophistication increases, so does the mandate for health care to operate in a constantly changing landscape.

The time for studying the problem is over. We need to retire a fragmented system that is not sufficiently effective, equitable, or manageable. Now is 
the time for primary care as a common good to lead health care forward. If we unite to implement primary care as a common good, I am confident that we will expand relationships, expand access, eliminate waste, and increase quality care for all Americans.

To see this article online, please go to: http://jabfm.org/content/ 34/5/1042.full.

\section{References}

1. National Academies of Sciences, Engineering, and Medicine. 2021. Implementing High-Quality Primary Care: Rebuilding the Foundation of Health Care. Washington, DC: The National Academies Press. Available from: https://doi.org/10.17226/25983.

2. Johansen ME, Kircher SM, Huerta TR. Reexamining the ecology of medical care. N Engl J Med 2016; 374:495-6.
3. Martin S, Phillips RL, Petterson S, Levin Z, Bazemore AW. Primary care spending in the United States, 2002-2016. JAMA Intern Med 2020;180:1019-20.

4. Organisation for Economic Co-operation and Development. Deriving preliminary estimates of primary care spending under the SHA 2011 framework. 2019. Paris, France: Organisation for Economic Cooperation and Development.

5. World Health Organization. Primary health care systems (PRIMASYS): case study from Rwanda, abridged version. Geneva: World Health Organization. Available from: https://www.who.int/alliance-hpsr/ projects/AHPSR-PRIMASYS-Rwanda-Abridged.pdf? ua=1. Published 2017. Accessed July 8, 2021.

6. Congressional Budget Office. The Outlook for Major Federal Trust Funds: 2020 to 2030. Available from: https://www.cbo.gov/system/files/2020-09/56523Trust-Funds.pdf. Published September 2020. Accessed July 8, 2021. 